This is an open access article under the terms of the CC-BY 3.0 License.

Peer review method: Double-Blind

Date of acceptance: November 16, 2020

Date of publication: January 08, 2021

Review article

DOI: https://www.doi.org/10.47305/JLIA2163090n

\title{
GEOPOLITICS OF NEAR-SPACE: INCREASING NATIONAL POWER THROUGH SPACEPLANE DEPLOYMENT
}

\author{
Bekim Nuhija \\ Faculty of Law, South East European University, North Macedonia \\ ORCID iD: https://orcid.org/0000-0001-7380-7495 \\ b.nuhija@seeu.edu.mk \\ Sami Mehmeti \\ Faculty of Law, South East European University, North Macedonia \\ ORCID iD: https://orcid.org/0000-0002-4212-9975 \\ s.memeti@seeu.edu.mk

\section{Stefani Stojchevska} \\ Faculty of Law, South East European University, North Macedonia \\ ORCID iD: https://orcid.org/0000-0002-6910-7039 \\ ss26215@seeu.edu.mk
}

\begin{abstract}
With the delimitation of airspace and outer space being a continuous issue, various arguments intend to analyze the viewpoint of the geopolitics of near-space being considered neither as part of Astropolitik, nor the geopolitics of airspace. Consequently, a comparative methodology in regards to the multidimensional objectives of geopolitics is followed: (1) evolving a theoretical military basis of spaceplane deployment; (2) examining the natural background of the geopolitics of near-space; (3) constructing the 'history-future' relation of the geopolitics of near-space; and (4) analyzing the increasing of America's national power through spaceplane deployment. Principle results obtained from the theoretical comparative methodology consequently determine the fundamental establishment of the geopolitics of near-space.
\end{abstract}

Keywords: Geopolitics; Near-Space; Military; Spaceplanes; National Power; International Relations 


\section{INTRODUCTION}

The true value of modern geopolitics is as a scholarly analysis of the geographical factors underlying international relations and guiding political interactions. Such an analysis does not determine the directions that statecraft must take. It does, however, present the desirable directions and alert policymakers to the likely impact of their decisions on these relations and interactions. Because geopolitics straddles two disciplines - geography and politics - its approaches vary according to frameworks of analysis common to each discipline. Since most early theories and concepts of geopolitics grew out of geographical thought, later applications by historians and political scientists often failed because they did not adapt their theories to the dynamic, complex nature of geographical settings (Cohen 2008, 11-12).

As the delimitation of airspace and outer space represents a continuous multidisciplinary issue, recent acknowledgments of the American Air Force's X-37B military spaceplane open new perspectives regarding the elaboration of geopolitics. The emergence of spaceplanes considers a comparative analysis for establishing a new branch by simultaneously incorporating its geographical characteristics, spaceplanes' practical military utilization, as well as US national politics and global influence. Theoretical adaptations must heavily rely upon the mesosphere not being entirely associated with airspace or outer space, as the geopolitics of near-space would primarily include a dynamic outline of establishing the relationship between man and geographical dominance, especially by military means, technology, and science. Its conceptual foundation would associate the expansion of regulated and strategized territorial boundaries toward a notorious environment that has often been ignored by both scientists and policymakers. To establish the geopolitics of near-space, a comparative methodology must be followed in regards to the multidimensional objectives of geopolitics. As geopolitics deals with basic aspects of the growth of civilization, its analysis in the form of a complete methodology has a fourfold objective: (1) to evolve a sound theoretical basis on which geopolitics could be developed as a systematic discipline; (2) to examine the nature of the development of contemporary regional and global geopolitics, including seabed and outer space; (3) to reconstruct the history of the geopolitics of any particular country or region or the globe; and (4) to analyze the national power of important countries. Thus, geopolitics has two aspects, theoretical and operative (Sen 1975, 2).

The aforementioned objectives can be adaptively analyzed upon the conceptualized geopolitics of near-space. However, both theoretical and operative aspects regarding such methodology cannot be equally scrutinized due to military spaceplanes not being often utilized during peacetime for research purposes on one hand, and not being ever utilized during warfare for military-related purposes, on the other. 
Such acknowledgments complement the theoretical aspect, allowing us to speculate, estimate, and predict the potential establishment of the geopolitics of nearspace, even though theory and practice often manifest a constructive correlation.

\section{THEORETICAL MILITARY BASIS OF SPACEPLANES OPERATING IN NEAR-SPACE}

The military can be an integral partner of a government; it can be the government itself, an external 'kingmaker', or it may be a subordinate element unable to exert power or control over a government. Regardless, the role of the military and its history affect how a culture views defensive and offensive military operations (National Security Agency 1998, 23).

While military security capabilities reflect national strengths, appropriate knowledge is parallel toward the particular terrains. Theoretical military applications and strategies must heavily rely on the mesosphere as a geographical issue, including spaceplanes' continuous technological developments for the geopolitics of near-space to represent a well-structured discipline. To fully comprehend its main theoretical military-based standpoints, we must analyze how governing forces would achieve domination, national possession, and control of space through the mesosphere and its national implications. Both defensive and offensive near-space military operations emphasize the expansion of national force branches to guarantee national security, particularly as a response to subsequent foreign space-faring hostile actions.

New geographic influences require the study of technological and economic developments that strengthen states through national forces. Geopolitics of near-space would include physical factors (altitude, temperature, gravity waves, atmospheric tides, weather) and simultaneously exclude cultural factors associated with the geopolitics of land (population, race, industry, religion, communication), which is understandable since human society cannot thrive regarding such an unfathomable environment. Nevertheless, at the heart of any serious geopolitical analysis is the question of the power and borders of states that in any final instance are enforced by military power (Bergesen 2018, 169). An aerospace force is comprised of both air and space systems and the people who employ and support those systems and have the full range of capabilities to control and exploit the aerospace continuum (US Air Force 2000, 3).

Envisioning an 'Aerospace Force' allows the manifestation of aerospace warfare and superiority by a particular space-faring nation, as a special military branch. Since the infamous X-37B military spaceplane belongs to the American Air Force, developing the geopolitics of near-space considers military spaceplanes as appropriate to a fully conceptualized 'Aerospace Force' according to their technological classification and geographical utilization, respectively. Unlike reusable space vehicles designed for commercial or scientific applications, a military spaceplane would complete missions 
including transportation, force projection, reconnaissance, and deployment of space assets supporting the strategic and tactical goals of theater commanders. Reliable access to space will drastically change how military goals are achieved (Rothermel 1997, 2). Near-space's potential for military aerospace operations during peacetime and wartime opens new dynamics of war within the military theory and creates new military capabilities in response to national security. The theoretical military basis of the geopolitics of near-space should not focus upon aerospace warfare itself, but the concept of near-space as an environment where aerospace warfare ideas are simultaneously based upon physical characteristics and geography. Consequentially, the purpose of military theory regarding the geopolitics of near-space would be to study, understand, explain and concern the potentials of aerospace warfare successes, primarily through military spaceplane deployment as components of military resources. While military theory conducts a multi-disciplinary analysis, sub-fields of military strategy, politics, international relations, legislation issues, operational processes, the dynamics of potential armed conflict between space-faring nations, national security or technological developments of military spaceplanes must revolve around the geography of near-space as an unfathomable environment, by influencing the creation of an effective and consistent theoretical basis concerning near-space potential military utilization.

\section{THE NATURAL BACKGROUND OF GEOPOLITICS OF NEAR-SPACE}

Geographical regions on Earth and in space are reasonably homogeneous areas containing distinctive topography, climate, vegetation, and cultural features (or lack thereof) that exert relatively uniform effects on military policies, plans, programs, and operations. Spacecraft crews become familiar with five geographic regions stacked one above the other as they fly through the troposphere, stratosphere, mesosphere, thermosphere, and exosphere en route to circumterrestrial space about 60 miles (95 kilometers) above Earth, where aerodynamic drag and frictional heat lose most of their significance (Collins 1998, sec. 3, para. 1-3).

A spaceplane is quite simply a vehicle that can fly as both an airplane in the atmosphere - generating lift from its wings - and as a spacecraft in a vacuum using rocket propulsion (America Space 2013). Since they focus on the mesosphere as the 'atmospheric border' between airspace and outer space, spaceplanes must adapt to near-space geographical characteristics to perform missions successfully. Such scientific and technological developments contribute to building one of the main theoretical standpoints of national governing forces belonging to prominent spacefaring nations that strive to achieve dominance in near-space during both peacetime and wartime. However, near-space vehicles need to be flexible, replaceable, and cost-effective, otherwise, their use may be very limited in military applications (Wang 2011, 15). 
The geostrategic importance of near-space allows its further research to provide answers for technologically improving spaceplanes. Consequently, the development of geopolitics of near-space would not be motivated upon the necessary dependence on man upon the mesosphere, as it would be about the increasing dynamics of spaceplanes' revolutionary utilization. The direction of geopolitical thoughts concerning near-space does not correlate with basic human survival. Instead, it promotes more advanced thoughts, such as dominating a challenging geographical region to operate within, technologically speaking. Another argument that additionally examines the development of geopolitics of near-space is to compare its fundaments with both the geopolitics of airspace and Astropolitik, to conclude why it must be appropriately separated based on atmospheric classification, similar as to how the $100-\mathrm{km}$ altitude ever since named the 'Karman Line' came thus into existence as the boundary separating Aeronautics and Astronautics (Fédération Aéronautique Internationale 2004). Namely, the geopolitics of air space, as a newly emerged geopolitical conceptualization, was inspired by the Russian-American advocate of strategic airpower - Major Alexander P. De Seversky, who in one of his most prominent books 'Victory through Air Power' (1942), claimed superiority of aviation power within air space, although being limited from both aspects of geography and equipment, as appropriately stated that it should be borne in mind that control of the skies is limited, in geographical extent, by the effective range of the conquering aviation. The reach of an air force, like the reach of a boxer's fist, can extend so far and no farther, depending on the range of the equipment (De Seversky 1942, 112). Regarding geopolitics of near-space, setting geopolitical limitation by the aspect of spaceplanes' capabilities to simultaneously operate in both airspace and outer space would be problematic, automatically 'expanding' state policy through natural geographical areas. Spaceplanes would need to operate specifically within the mesosphere's predicted atmospheric altitudes to determine near-space as a 'limited' geographical region. The conceptualization of geopolitics of near-space possesses a 'constant vs. variable' status, as appropriately compared to the contrasting mathematical values. While constants do not change their values over time, variables, on the other hand, change their values depend on the given equation. Similarly enough, if spaceplanes operate only within the mesosphere's atmospheric altitudes, the geopolitics of near-space would obtain a 'constant' status. However, if spaceplanes are predicted to operate in both airspace and outer space, then the geopolitics of near-space would obtain a 'variable' status. The lines between the 'constant vs. variable' statuses are blurred by spaceplanes' technological capabilities and further developments. Moreover, it is emphasized how De Seversky manages to describe air space as a particular geographical area, where political and geographical differentiation of contrasting regions should not necessarily influence the identification of specific non-military and military aims, along with their ultimate achievement: 
The air, it cannot be too often repeated, is a separate element, distinct from land and sea - an element with its space relations, its laws, and problems. It is a continuous and uninterrupted element enveloping the entire globe; strategically speaking, every political division, and every differentiation between air-over-land and air-over-water is artificial and meaningless (De Seversky 1942, 263).

In parallel, the mesosphere is already regarded as the separate, third layer of the atmosphere, characterized by particular environmental features and natural phenomena. Additionally, the concept of 'Aerospace Law' would represent a new legal regime applicable to all near-space operations, particularly performed by spaceplanes. It would differentiate near-space from airspace and outer space, although their delimitation represents a continuous issue regarding both scientific and legal disciplines and contribute to the elimination of legal impracticalities applying to aerospace vehicles, as their operations would be rigorously performed in neither airspace nor outer space. The establishment of Astropolitik, on the other hand, was inspired by the increasingly rapid technological developments that enabled the beginnings of space exploration.

Hence, the launching of the first artificial satellite Sputnik 1 in 1957 resulted in the birth of space law. From a geopolitical standpoint, space exploration indicates the extension of human reach and the governing of the areas in question, while allowing many national privileges of military, technological, scientific, legal, and political background. The role of space exploration primarily contributes to Astropolitik to find its foundations in the classical study of geopolitics, as well as further manifestations of international relations among spacefaring nations.

In its narrowest construct, Astropolitik is the extension of primary nineteenth-and twentieth-century theories of global geopolitics into the vast human conquest of outer space. In a more general and encompassing interpretation, it is the application of the prominent and refines realist vision of state competition into outer space policy, particularly the development and evolution of a legal and political regime for humanity's entry into the cosmos (Dolman 2002, 1).

Regarding the cartography of outer space, four essential types of orbits are taken into consideration: low altitude (between $150 \mathrm{~km}$ and $800 \mathrm{~km}$ above the Earth's surface); medium-altitude (ranging from $800 \mathrm{~km}-35,000 \mathrm{~km}$ ); high-altitude (above 35,000 km); and highly elliptical (with a perigee of $250 \mathrm{~km}$ and an apogee of $700,000 \mathrm{~km}$ ). (Duvall 2009 , 44) Spaceplanes' capability of accessing low-Earth orbit allows them to achieve predicted goals within that altitude. However, it would not represent their sole purpose, repeatedly associating such circumstances with the 'constant vs. variable' statuses. Extraterrestrial capabilities do not contribute much in strengthening space dominance, but can significantly influence national aerospace dominance. Between geography and geopolitics, the increasingly rapid technological developments are what currently 
represents the most solid factor for potentially establishing the geopolitics of nearspace. From both comparisons, it is noticed that the main reasons for the emergence of both the geopolitics of air space and Astropolitik differ. While the emergence of the geopolitics of air space contains a military background, the emergence of Astropolitik contains a semi-military background, giving particular emphasis to the scientific and technological development of artificial satellites.

\section{"HISTORY-FUTURE" RELATION IMPACTS OF GEOPOLITICS OF NEAR-SPACE}

The available evidence of near-space exploration provides the theoretical study of a new geopolitical model concerning its geographical area. Similar to historical developments of geopolitics, the impact of near-space upon contemporary human necessities of scientific, economic, and military background contribute to improving the notion of national power. However, near-space exploration would not necessarily 'reconstruct' the history of the geopolitics of any particular nation, as it would settheoretical and practical implications for the US to rather 'construct' the history of the geopolitics of near-space. Consequently, establishing a 'history-future' relation allows for the geopolitics of near-space to be perceived as a futuristic geopolitical theory, while simultaneously setting the foundations of its historical developments. Additionally, it is presumed for the $\mathrm{X}-37 \mathrm{~B}$ military spaceplane to characterize the beginnings of the geopolitics of near-space. Therefore, despite the terminological association to military objectives, as officially announced by the Air Force, the primary objectives of the X-37B are twofold; reusable spacecraft technologies for America's future in space and operating experiments which can be returned to, and examined, on Earth (US Air Force 2020).

Explaining human history through aerospace achievements emphasized the relationship between man and near-space as a challenging area to explore and dominate. Near-space exploration would dictate the course of its geopolitical application to influence the relevance of international relations, particularly with the US The future utilization of geopolitics of near-space, additionally, would also determine the extent to which geographical opportunities will be exploited depends on the strategy. That is a concern with the deployment and use of armed forces to attain particular political objectives (Gray and Sloan 1999, 2). Nevertheless, aerospace has become another terrain for a power struggle, and, similar to other systems, it is made up of various spatial elements that are organically connected. Based on their characteristic traits, these spatial elements may be suitable for accommodating and operating space tools that either serve military, civil, scientific, health care, and meteorological, etc. purposes, or, for sketching future alternative possibilities, as well as solutions for humankind's survival and power strategies in their relation to one another (Szilágyi 2017). 


\section{THE INCREASEMENT OF AMERICA'S NATIONAL POWER THROUGH HYBRID AEROSPACE VEHICLES}

In the study of international relations, the term 'power' usually refers to national power - the power a state possesses to obtain compliance from other states. A state may use its power to promote and protect its vital interests in international politics, to save its population from external aggression, and to cooperate with other nations (Aneek 2010, 59). However, national power is regarded differently within hierarchical levels and cannot be equally associated among world nations. The great power system may be defined as the set of relationships among great powers, with their rules and patterns of interaction (a subset of the international system). Great powers have special ways of behaving and of treating each other that do not apply to other states. The most powerful of great powers, those with truly global influence, have been called 'superpowers'. This term generally meant the United States and the Soviet Union during the Cold War, but most IR scholars now consider the United States to be the world's only superpower (Goldstein and Pevehouse 1994, 12). Furthermore, an eloquent exposition of the essence of hegemony is offered by William Safire. Safire comments that the word 'hyperpower' was coined by the French foreign minister Hubert Vedrine in 1999 to describe the power of the United States, which no longer could be adequately described by the term 'superpower' (Reid 2003, 82). Nevertheless, the main question within this chapter is as follows: How would the geopolitics of near-space increase America's national power and more importantly, through which element of national power?

One of the aims of geopolitics is to emphasize that political predominance is a question of not just having power in the sense of human or material resources, but also of the geographical context within which that power is exercised (Gray and Sloan 1999, 2). The geographical context, however, primarily acknowledges US national territory and does not directly associate with the technological development of spaceplanes or the scientific research of near-space. To identify the specific element of national power, it is necessary to look over and simultaneously classify them by origin and application. The national power of a state is the product of several elements. These are: (1) geography; (2) population; (3) natural resources; (4) popular support; (5) national character; (6) technology and military strength; (7) ideology; and (8) leadership. These elements are dependent on one another, and their combined positive contributions can make a nation powerful (Aneek 2010, 59).

The social element of technology and military strength perfectly describes spaceplanes' technological advancements as aerospace vehicles, as well as their deployment within the U.S. military. Additionally, military spaceplane deployment does not necessarily associate with conducting missions and operations of hostile nature. On the contrary, dual perceptions significantly contribute during peacetime (achieving 
scientific research objectives) as much as they might contribute during wartime (achieving military objectives) since the military strength of the US is defined primarily by the global reach, power, and awareness that are derived from its capabilities in air and space (Air Force Magazine 1999). Such technological, scientific and military leverages further enhance the notion of national aerospace superiority. Everett Dolman, widely regarded as an indispensable thinker in this field, regards himself as a modernday representative of political realism, as well as the intellectual heir of the classical geopolitical thinkers - primarily Alfred Thayer Mahan, Sir Halford Mackinder, and Nicholas Spykman - whose work he further develops in his own. His book published under the title 'Astropolitics', bears the subtitle 'Classical Geopolitics in the Space Age'. Dolman adapted Mackinder's sentence about the heartlands, widely regarded as a scientific adage, to our days. He emphasizes the significance of aerospace when he writes: "Who controls Low-Earth Orbit controls Near-Earth Space. Who controls NearEarth Space dominates Terra. Who dominates Terra determines the destiny of humankind" (Szilágyi 2017). Despite Dolman's standpoint, the concept of the US possessing such great national power is criticized. For instance, Verdine is quoted as complaining about such hegemonic power: "We cannot accept a politically unipolar world, nor a culturally uniform world, nor the unilateralism of a single hyperpower" (Reid 2003, 82). Nevertheless, by acknowledging the Air Force's X-37B military spaceplane's record-breaking duration in near-space, the US has proven to possess all means necessary to establish national dominance upon the mesosphere concerning other spacefaring nations' future attempts of near-space exploration.

\section{CONCLUSION}

Principle results obtained from the comparative methodology concerning multidimensional fourfold objective conclude the potential establishment of the geopolitics of near-space, primarily based upon effective-resource spaceplane deployment. Both theoretical and practical understandings accumulate various elements of theoretical military basis, geographical characteristics, and natural phenomena, theoretical 'history-future' relation, as well as a national power, enabling the development of the geopolitical theory as a scientific discipline to study the mesosphere - a rather challenging geographical area - for its ultimate scientific and military utilization, consequently changing the realm of international relations.

Establishing the geopolitics of nears space is highly justifiable, as it is theoretically impractical to consider such political and military objectives as manifestations of the geopolitics of airspace or Astropolitik. Moreover, a significant increase in technological advancements regarding aerospace vehicles is evident, as commercial and military interests have begun to develop operating systems in near-space. Such systems include suborbital vehicles, stratospheric balloons, pseudo-satellites, and high-altitude drones. 
Some will operate a few minutes, hours, weeks, months, or years (Dempsey and Manoli 2018, 235). One of the definite outcomes from the establishment of the geopolitics of near-space is to increase national power by spaceplane deployment with military strength. The geographical issue of the mesosphere, however, does not only manifest military-diplomatic nature in both theory and practice since its subject matter demonstrates multidimensional characteristics, which requires further analysis. And while the nature of geopolitics firmly transcends toward near-space, the gravity of its benefits will be primarily felt over the succeeding decades. 


\section{REFERENCES}

1. America Space. 2013. "A Brief History of Spaceplanes". Accessed June 23. https://www.americaspace.com/2013/06/10/a-brief-history-of-spaceplanes/

2. Aneek, C. 2010. International Relations Today: Concepts and Applications. Delhi: Pearson.

3. Air Force Magazine. 1999. "An Aerospace Force for the Nation". Accessed July 26. https://www.airforcemag.com/article/1199edit/

4. Bergesen, Albert J. 2018. "From Geopolitics to Astropolitics". In The Return of Geopolitics, edited by Albert J. Bergesen and Christian Suter, 169-182. Zürich: Lit Verlag.

5. Cohen, Saul, B. 2008. Geopolitics: The Geography of International Relations. Lanham: Rowman \& Littlefield Publishers.

6. Collins, John, M. 1998. Military Geography for Professionals and the Public. Washington: Potomac Books, Inc.

7. Cryptology Quarterly - National Security Agency. 1998. "Intelligence Analysis: Does NSA Have What It Takes?" NSA/CSSM 123-2: 1-32.

8. De Seversky, A. 1942. Victory through AirPower. New York: Simon and Schuster.

9. Duvall, R. D., Havercroft, J., \& Duvall, R. D. 2009. "Critical Astropolitics: The Geopolitics of Space Control and the Transformation of State Sovereignty." In Securing Outer Space: International Relations Theory and the Politics of Space, edited by Natalie Bormann and Michael Sheehan, 42-58. New York: Routledge.

10. Dempsey, Paul S. and Maria Manoli. 2018. "Suborbital Flights and the Delimitation of Air Space Vis-à-vis Outer Space: Functionalism, Spatialism and State Sovereignty." Annals of Air and Space Law, vol. XLII: 209-251.

11. Dolman, E. C. 2002. Astropolitik: Classical Geopolitics in the Space Age. London: Frank Cass Publishers.

12. Fédération Aéronautique Internationale. 2004. "Presentation of the Karman separation line, used as the boundary separating Aeronautics and Astronautics". Accessed June 23. https://web.archive.org/web/20110809093537/http://www.fai.org/astronautics/10 Okm.asp

13. Gray, Collins, S., and Sloan, G. 1999. Geopolitics, Geography and Strategy. New York: Routledge.

14. Goldstein, S. J. and Pevehouse, C. J. 1994. International Relations: International Edition. New York: Pearson.

15. Reid, J.I.M. 2003. Religion and Global Culture: New Terrain in the Study of Religion and the Work of Charles H. Long. Lanham: Lexington Books. 
16. Rothermel, Scott, A. 1997. "Architecture, Design, and Implementation of a Rapidly Prototyped Virtual Environment for a Military Spaceplane". MA Thesis, Air Force Institute of Technology, Ohio.

17. Sen, Debabrata. 1975. Basic Principles of Geopolitics and History: Theoretical Aspect of International Relations. Delhi: Concept Publishing Company.

18. Szilágyi, István. 2017. "The Geopolitics of Five Dimensional Space". Accessed June 22. http://www.geopolitika.hu/en/2017/08/15/the-geopolitics-of-fivedimensional-space/

19. U.S. Air Force. 2000. "The Aerospace Force: Defending America in the $21^{\text {st }}$ Century:--a white paper on aerospace integration". Washington: Department of the Air Force.

20. U.S. Air Force. 2020. "X-37B Orbital Test Vehicle". Accessed June 22. https://www.af.mil/About-Us/Fact-Sheets/Display/Article/104539/x-37b-orbitaltest-vehicle/

21. Wang, Wen-Qin. 2011. Near-Space Remote Sensing: Potential and Challenges. Heidelber: Springer-Verlag. 